\title{
Prevalence and 15-year incidence of retinopathy and associated characteristics in middle-aged and elderly diabetic men
}

\author{
LUTZA YANKO, ${ }^{12}$ URI GOLDBOURT,$^{3}$ ISAAC C. MICHAELSON,${ }^{2}$ \\ AMIRAM SHAPIRO,${ }^{1}$ AND SHLOMIT YAARI ${ }^{3}$ \\ From the ${ }^{1}$ Department of Ophthalmology and the ${ }^{2}$ Jerusalem Institute for the Prevention of \\ Blindness, Hadassah University Hospital and Hebrew University Hadassah Medical School, Jerusalem; \\ the ${ }^{3}$ Heart Institute, Sheba Medical Center, Tel Hashomer; and Sackler School of Medicine, \\ Tel Aviv University, Israel
}

SUMMARY We examined 178 men for the presence of diabetic retinopathy during 1978-80. They had been part of a group of 205 men from the Jerusalem area, diagnosed as being diabetic or having an abnormal glucose tolerance test in the Israel Ischaemic Heart Disease Project, a 5-year epidemiological investigation of Israeli male government employees. Seventy-four (42\%) had diabetic retinopathy as determined by direct and indirect ophthalmoscopy, 3-mirror contact lens examination, and fundus photography. Those with and without retinopathy were compared for clinical, biochemical, behavioural, and biographical variables measured subsequently in 1963, 1965 , and 1968. We found no significant differences between the 2 groups with respect to antecedent Quetelet index, blood pressure, peripheral vascular disease, blood lipids, haematocrits, smoking habits, area of birth, and education. Statistically significant differences between men with and without retinopathy were found for severity of carbohydrate metabolic intolerance at identification, duration of the metabolic abnormality, age, casual glucose values, and serum uric acid levels. Low serum uric acid appears to precede the incidence of diabetic retinopathy and to decline further as the disease progresses.

Diabetic retinopathy is a major cause of visual impairment and blindness in economically advanced countries. It is the commonest cause of newly reported blindness in the 41-60 age group, ${ }^{1}$ accounting for at least $12 \%$ of all new cases of blindness yearly. Considerable differences in rates of retinopathy among diabetics have been reported, ${ }^{2-5}$ but studies attempting to evaluate the possible causes of these differences are inconclusive.

This follow-up study was undertaken $(a)$ to investigate the prevalence and incidence of retinopathy in a group of men diagnosed as having diabetes or an abnormal glucose tolerance test (GTT) during the Israel Ischemic Heart Disease Project (IIHDP) survey, and $(b)$ compare diabetics with retinopathy to diabetics without retinopathy for clinical, biochemical, behavioural, and sociodemographic Correspondence to Dr Lutza Yanko, Department of Ophthalmology, Hadassah University Hospital, Jerusalem, Israel. variables measured during 3 previous successive examinations.

By studying diabetics with and without retinopathy who were examined repeatedly many years ago we attempt to support the hypothesis that a factor associated with the development of retinopathy may be present before any signs of the disease occur. These may even disappear after the retinopathy develops.

\section{Materials and methods}

A prospective epidemiological investigation was carried out on 10059 men aged 40 to 65 by the IIHDP during 1963-8. ${ }^{6}$ Inhabitants of the Jerusalem, Tel Aviv, and Haifa areas, civil servants and municipal employees, underwent 3 examinations in 1963, 1965, and 1968. The participants were born in 6 predefined 759 
Table 1 Criteria for diagnosis of diabetes based on a scoring system for glucose tolerance tests

\begin{tabular}{|c|c|c|c|c|c|c|}
\hline \multirow[t]{2}{*}{ Method } & \multicolumn{2}{|l|}{ Fasting value } & \multicolumn{2}{|l|}{ 1-hour value } & \multicolumn{2}{|l|}{ 2-hour value } \\
\hline & $(m g / 100 m l)$ & (Score) & $(m g / 100 m l)$ & (Score) & $(m g / 100 m l)$ & (Score) \\
\hline \multirow{3}{*}{$\begin{array}{l}\text { Glucose oxidase or } \\
\text { Somogyi-Nelson }\end{array}$} & $\geqslant 110$ & 1 & $\geqslant 170$ & $1 / 2$ & $\geqslant 120$ & $1 / 2$ \\
\hline & 100 to 109 & $1 / 2$ & 160 to 169 & 0 (Abnormal) & 100 to 119 & 0 (Abnormal) \\
\hline & $\leqslant 99$ & 0 & $\leqslant 159$ & 0 & $\leqslant 99$ & 0 \\
\hline \multirow[t]{3}{*}{ Autoanalyzer (Hoffman) } & $\geqslant 120$ & 1 & $\geqslant 180$ & $1 / 2$ & $\geqslant 130$ & $1 / 2$ \\
\hline & 110 to 119 & $1 / 2$ & 170 to 179 & 0 (Abnormal) & 110 to 129 & 0 (Abnormal) \\
\hline & $\leqslant 109$ & 0 & $\leqslant 169$ & 0 & $\leqslant 109$ & 0 \\
\hline \multirow[t]{3}{*}{ Hagedorn-Jensen } & $\geqslant 130$ & 1 & $\geqslant 200$ & $1 / 2$ & $\geqslant 140$ & $1 / 2$ \\
\hline & 120 to 129 & $1 / 2$ & 180 to 199 & 0 (Abnormal) & 120 to 139 & 0 (Abnormal) \\
\hline & $\leqslant 119$ & 0 & $\leqslant 179$ & 0 & $\leqslant 119$ & 0 \\
\hline
\end{tabular}

Scores are obtained by addition: a score of $1,1 \frac{1}{2}$, or 2 indicates diabetes; a score of 0 (abnormal) or $1 / 2$ indicates abnormal glucose tolerance; a score of 0 without the designation (abnormal) is normal (no diabetes).

SI conversion: glucose $\mathrm{mg} / 100 \mathrm{ml} \times 0 \cdot 0555=\mathrm{mmol} / \mathrm{l}$.

Middle East (excluding Israel), Central Europe, South Eastern Europe, and North Africa. This investigation provided us with approximately 120 variables for analysis.

The diagnostic procedure for and the severity classification of carbohydrate intolerance have been reported. ${ }^{78} \mathrm{~A}$ diagnosis of diabetes was based on a scoring system for GTT (Table 1) or, when GTT data were not available, on 3 diabetic abnormalitiesusually 3 abnormal glucose values while fasting (Table 2). The criteria for classification of the severity of the diabetes are summarised in Table 3.
In 1965 an ophthalmological study was carried out among the 2220 participants of the Jerusalem area. ${ }^{9}$ This study included a fundus photograph of 6 standard fields of one eye offered to all subjects who came for examination during a 6-month period. Of the 1200 subjects examined 1092 had fundus photography. The slides of 874 are available and suitable for analysis. Owing to an unfortunate mailing accident the slides of 188 subjects were lost. There is no reason to suspect bias due to this loss. Another 30 were unsuitable for analysis. ${ }^{10}$

Our diabetic retinopathy study was confined to the

Table 2 Criteria for diagnosis of diabetes based on 3 diabetic abnormalities*

\begin{tabular}{|c|c|c|c|c|c|}
\hline \multirow[t]{2}{*}{ Method } & & \multirow{2}{*}{$\begin{array}{l}2 \text { Fasting values } \\
(\mathrm{mg} / 100 \mathrm{ml})\end{array}$} & \multicolumn{3}{|l|}{ Other criteria } \\
\hline & & & $\begin{array}{l}\text { l Fasting value } \\
(m g / 100 m l)\end{array}$ & $\begin{array}{l}\text { l Casual value } \\
(\mathrm{mg} / 100 \mathrm{ml})\end{array}$ & $\begin{array}{l}\text { History and/or } \\
\text { treatment }\end{array}$ \\
\hline \multicolumn{2}{|c|}{$\begin{array}{l}\text { Glucose oxidase or Somogyi-Nelson } \\
\text { Autoanalyzer (Hoffman) } \\
\text { Hagedron-Jensen }\end{array}$} & $\begin{array}{l}\geqslant 110 \\
\geqslant 120 \\
\geqslant 130\end{array}$ & $\begin{array}{l}\geqslant 130 \\
\geqslant 140 \\
\geqslant 150\end{array}$ & $\begin{array}{l}\geqslant 160 \\
\geqslant 170 \\
\geqslant 180\end{array}$ & $\begin{array}{l}\text { Positive } \\
\text { Positive } \\
\text { Positive }\end{array}$ \\
\hline \multicolumn{6}{|c|}{$\begin{array}{l}\text { *Diabetes was diagnosed if there were } 2 \text { fasting values equal to or greater than those indicated, plus any one of the other criteria. } \\
\text { SI conversion: glucose } \mathrm{mg} / 100 \mathrm{ml} \times 0.0555=\mathrm{mmol} / \mathrm{l} \text {. }\end{array}$} \\
\hline \multicolumn{6}{|c|}{ Table 3 Criteria for the classification of severity of diabetes } \\
\hline \multirow{3}{*}{$\begin{array}{l}\text { Categories of } \\
\text { diabetic severity }\end{array}$} & \multirow{3}{*}{$\begin{array}{l}\text { Glucose tolerance } \\
\text { test }\end{array}$} & \multicolumn{4}{|l|}{ Other criteria* } \\
\hline & & \multirow{2}{*}{ Fasting $(H-J)$} & \multicolumn{3}{|c|}{ Additional requirements } \\
\hline & & & Fasting $(H-J)$ & Casual $(S-N)$ & $\begin{array}{l}\text { History and/or } \\
\text { treatment }\end{array}$ \\
\hline $\begin{array}{l}\text { Definite diabetes } \\
\text { Probable diabetes } \\
\text { Possible diabetes } \\
\text { Abnormal GTT } \\
\text { Normal }\end{array}$ & $\begin{array}{l}2 \text { points } \\
11 / 2 \text { points } \\
1 \text { point } \\
1 / 2 \text { or abnormal } \\
\text { Normal at all levels }\end{array}$ & $\begin{array}{l}\geqslant 130 \times 2+ \\
\geqslant 130 \times 2+ \\
\geqslant 130 \times 1+ \\
\leqslant 120 \times 3\end{array}$ & $\begin{array}{l}\geqslant 150 \\
\geqslant 130 \\
\geqslant 130\end{array}$ & $\begin{array}{l}\text { or } \geqslant 200 \\
\text { or } \geqslant 160 \\
\text { or } \geqslant 160\end{array}$ & $\begin{array}{l}\text { or Tablets insulin } \\
\text { or positive history } \\
\text { or positive history }\end{array}$ \\
\hline
\end{tabular}

${ }^{*}$ Alternative criteria in the event of a glucose tolerance test being unavailable. $\mathrm{H}-\mathrm{J}=\mathrm{Hagedorn}-\mathrm{J}$ ensen method. $\mathrm{S}-\mathrm{N}=\mathrm{Somogy}-\mathrm{Nelson}$ method. 
Table 41965 prevalence of retinopathy in photographed men of the diabetic study group

\begin{tabular}{|c|c|c|c|c|c|c|}
\hline \multirow[t]{3}{*}{ Diabetic study group } & \multirow{3}{*}{$\begin{array}{l}\text { Total } \\
\text { (a) }\end{array}$} & \multicolumn{5}{|c|}{ Photographed in 1965} \\
\hline & & \multicolumn{3}{|c|}{ Total } & \multicolumn{2}{|c|}{ With retinopathy } \\
\hline & & $\begin{array}{l}\text { No. } \\
\text { (b) }\end{array}$ & ' & $\begin{array}{l}\% \\
\text { of }(a)\end{array}$ & No. & $\begin{array}{l}\% \\
o f(b)\end{array}$ \\
\hline Examined in 1978-1980 & 178 & 77 & & 43 & 7 & 9 \\
\hline Alive-not examined $1978-80$ & 27 & 13 & & 48 & 1 & 8 \\
\hline Deceased during follow-up & 85 & 22 & & 26 & 6 & 27 \\
\hline Total & 290 & 112 & & 39 & 14 & 12 \\
\hline
\end{tabular}

participants of the IIHDP living in the Jerusalem area, both at the time of the initial survey and in 1978-80. All the patients were aged 40 years and over in 1963. They were diagnosed as diabetic or showed an abnormal GTT during any of the subsequent examinations. 112 of the 290 participants conforming with these criteria were photographed during the ophthalmological study in 1965. The colour slides of the retina were examined during the present study to determine if retinopathy had existed at the time (Table 4).

A significant issue in interpreting the results of this paper is the possibility of segregating the diabetic retinopathy cases already present at the beginning of the IIHDP from those developing subsequently through 1978-80. We observed that approximately 1 in $11(9 \%)$ men of those examined during this study had already developed retinopathy in 1965 (Table 4). As the prevalence for those examined in 1978-80
(Table 5) is about $42 \%$ (Table 6), it would appear that roughly a fifth of those cases were already present in 1965. Therefore the relationship of the different variables to diabetic retinopathy is an association with a group of cases that consists of approximately $80 \%$ incident cases in a 15-year time span. Thus in a high percentage the various measurements taken have preceded the onset of retinopathy, although the associations are not fully equivalent to those computed in a classical prospective design where only measurements in persons free of the disease are considered for identification of risk factors.

Each of the 290 IIHDP participants still living in the Jerusalem area was invited for an interview and examination. Ocular examinations included visual acuity, applanation tonometry, and slit-lamp biomicroscopy of the anterior segment. Direct and indirect ophthalmoscopy were performed after full dilatation of the pupils. In those cases where fundus

Table 5 The diabetic study group by age and examination status

\begin{tabular}{|c|c|c|c|c|c|c|}
\hline \multirow[t]{2}{*}{ Age in 1963} & \multirow[t]{2}{*}{ No. } & \multirow[t]{2}{*}{$\%$} & \multicolumn{2}{|c|}{ Alive throughout follow-up } & \multicolumn{2}{|c|}{ Examined in $1978-80$} \\
\hline & & & No. & $\%$ & No. & $\begin{array}{l}\% \\
\text { (of those alive } \\
1978-80 \text { ) }\end{array}$ \\
\hline $40-49$ & 94 & $100 \cdot 0$ & 85 & 90.4 & 76 & 89.4 \\
\hline $50-59$ & 147 & $100 \cdot 0$ & 99 & $67 \cdot 3$ & 88 & $88 \cdot 9$ \\
\hline $60+$ & 49 & $\quad 100 \cdot 0$ & 21 & $42 \cdot 9$ & 14 & $66 \cdot 7$ \\
\hline Total & 290 & $100 \cdot 0$ & 205 & $70 \cdot 7$ & 178 & $86 \cdot 8$ \\
\hline
\end{tabular}

Table 6 1978-80 prevalence of retinopathy by age and duration of diabetes

\begin{tabular}{|c|c|c|c|c|c|c|c|c|c|c|c|c|}
\hline \multicolumn{4}{|l|}{ Total } & \multicolumn{9}{|c|}{ Duration } \\
\hline \multirow[t]{3}{*}{ Age } & \multirow[t]{3}{*}{ No. } & \multicolumn{2}{|c|}{ With retinopathy } & \multicolumn{3}{|c|}{$11-13$ Years } & \multicolumn{3}{|c|}{ 14-16 Years } & \multicolumn{3}{|c|}{$>16$ Years } \\
\hline & & \multirow[t]{2}{*}{ No. } & \multirow[t]{2}{*}{$\%$} & \multirow[t]{2}{*}{ No. } & \multicolumn{2}{|c|}{ With retinopathy } & \multirow[t]{2}{*}{ No. } & \multicolumn{2}{|c|}{ With retinopathy } & \multirow[t]{2}{*}{ No. } & \multicolumn{2}{|c|}{ With retinopathy } \\
\hline & & & & & No. & $\%$ & & No. & $\%$ & & No. & $\%$ \\
\hline $55-64$ & 76 & 37 & 49 & 34 & 11 & 32 & 13 & 7 & 54 & 29 & 19 & 66 \\
\hline $65-74$ & 88 & 32 & 36 & 34 & 5 & 15 & 21 & 7 & 33 & 33 & 20 & 61 \\
\hline $75+$ & 14 & 5 & 36 & 5 & 1 & & 3 & 2 & & 6 & 2 & \\
\hline Total & 178 & 74 & 42 & 73 & 17 & 23 & 37 & 16 & 43 & 68 & 41 & 60 \\
\hline
\end{tabular}


photographs could not be taken because of opaque media or for technical reasons, a 3-mirror contacts lens examination was performed. Whenever possible, information on the ocular condition of the persons who did not respond to the third invitation was obtained from the Eye Clinics and Internal Departments records of 2 main hospitals and the Sick Fund Diabetic Follow-up Clinic in Jerusalem.

The patients were classified in the following way. The severity of the diabetes was divided into 4 categories: definite diabetes, probable diabetes, possible diabetes, and abnormal GTT (Table 3). Duration of diabetes was calculated from the date of diagnosis of diabetes or abnormal GTT to the date of the last ophthalmological examination in 1978-80. The patients were divided into 3 groups: $11-13$ years (those diagnosed in 1968, having been negative in 1963 and 1965), 14-16 (those diagnosed in 1965, having been negative in 1963), and over 16 years (newly diagnosed or with a known history in 1963).

As a result of the fundal examination the patients were classified in 3 groups: $O$ (absent), indicating no retinal lesions on the fundus photographs and/or the retinal examination; $Q$ (questionable), indicating the presence of something resembling a lesion which could not be positively identified; $P$ (present), if one or more lesions were identified. L.Y. and I.C.M. classified the subjects independently and found no obvious discrefancies in their results. Only those subjects classified $\mathbf{P}$ for one or both eyes were considered to have diabetic retinopathy.

The severity of diabetic retinopathy was graded in 3 categories: $I$, in which one or more microaneurysms in either eye was the only diabetic retinal lesion; II, in which retinal haemorrhages, soft and/or hard exudates, venous calibre abnormalities or intraretinal microvascular abnormalities along with microaneurysms were present; III, in which lesions characteristic of proliferative retinopathy such as neovascularisation, retinal elevation, preretinal haemorrhage, or vitreous haemorrhages were present.

We compared the mean values of several clinical, biochemical, behavioural, and sociodemographic variables in men with and without retinopathy, using measurements performed in 1968 when all the study participants were diabetic or had an abnormal GTT. Analysis of measurements from 1963 and 1965 revealed similar findings and are not reported. Retinopathy/nonretinopathy comparisons for serum uric acid were made with measurements from 1963 , 1965 , and 1968 , since a trend relating the serum uric acid level to the duration of diabetes was observed. ${ }^{11}$

\section{Results}

Of the 290 participants of the IIHDP Jerusalem group diagnosed as having diabetes or an abnormal GTT in $1963-8,205(71 \%)$ were alive during the present 1978-80 diabetic retinopathy follow-up study. 178 $(87 \%)$ of those alive were examined at that time (Table 5).

The prevalence of retinopathy in the subjects examined in this study was $9 \%$ in 1965 (Table 4) and $42 \%$ in 1978-80 (Table 6). The fact that we have these data for both the examination periods offers us a unique opportunity to extrapolate the nearly $80 \%$ incidence of retinopathy among these patients over a 15 -year time span. The distribution of retinopathy by age and duration of diabetes in 1978-80 is also shown in Table 6. The prevalence of retinopathy has increased from $23 \%$ in 11-13 years of metabolic abnormality to $43 \%$ in the $14-16$ years category and $60 \%$ in those of more than 16 years. The rate of retinopathy decreased with age, dropping from $49 \%$ in the $55-64$ age group to $36 \%$ in the 2 groups of men over 65 years old. The decrease with age was apparent in each duration group whenever the numbers were large enough to compare. There was little difference in the prevalence of retinopathy among men having diabetes for more than 16 years, between the 55-64 and 65-74 age groups.

The relationship between the prevalence of retinopathy found in 1978-80 and the severity of antecedent diabetes in 1963-68 according to the duration

Table 7 Prevalence of retinopathy by diabetic category and duration in 1978-80

\begin{tabular}{|c|c|c|c|c|c|c|c|c|c|c|c|c|}
\hline \multicolumn{4}{|l|}{ Total } & \multicolumn{9}{|c|}{ Duration (years) } \\
\hline \multirow{3}{*}{$\begin{array}{l}\text { Original diabetic } \\
\text { category (defined } \\
1963,1965 \text { and 1968) }\end{array}$} & \multirow[t]{3}{*}{ No. } & \multicolumn{2}{|c|}{ With retinopathy } & \multicolumn{3}{|c|}{$11-13$} & \multicolumn{3}{|c|}{$14-16$} & \multicolumn{3}{|c|}{$>16$} \\
\hline & & \multirow[t]{2}{*}{ No. } & \multirow[t]{2}{*}{$\%$} & \multirow[t]{2}{*}{ No. } & \multicolumn{2}{|c|}{ With retinopathy } & \multirow[t]{2}{*}{ No. } & \multicolumn{2}{|c|}{ With retinopathy } & \multirow[t]{2}{*}{ No. } & \multicolumn{2}{|c|}{ With retinopathy } \\
\hline & & & & & No. & $\%$ & & No. & $\%$ & & No. & $\%$ \\
\hline $\begin{array}{l}\text { Definite diabetes } \\
\text { Probable diabetes } \\
\text { Possible diabetes } \\
\text { Abnormal GTT } \\
\text { Total }\end{array}$ & $\begin{array}{r}86 \\
12 \\
32 \\
48 \\
178\end{array}$ & $\begin{array}{r}48 \\
7 \\
10 \\
9 \\
74\end{array}$ & $\begin{array}{l}56 \\
58 \\
31 \\
19 \\
42\end{array}$ & $\begin{array}{r}17 \\
4 \\
14 \\
38 \\
73 \\
73\end{array}$ & $\left.\begin{array}{r}8 \\
2 \\
2 \\
5 \\
17\end{array}\right\}$ & $\begin{array}{l}13 \\
23\end{array}$ & $\begin{array}{r}18 \\
5 \\
10 \\
4 \\
37\end{array}$ & $\left.\begin{array}{r}8 \\
3 \\
4 \\
1 \\
16\end{array}\right\}$ & $\begin{array}{l}36 \\
43\end{array}$ & $\begin{array}{r}51 \\
3 \\
8 \\
6 \\
68\end{array}$ & $\left.\begin{array}{r}32 \\
2 \\
4 \\
3\end{array}\right\}$ & $\begin{array}{l}50 \\
60\end{array}$ \\
\hline
\end{tabular}


Table 8 Distribution of types of retinopathy by diabetic category

\begin{tabular}{|c|c|c|c|c|c|c|c|c|}
\hline \multirow[t]{3}{*}{ Type of retinopathy } & \multicolumn{8}{|c|}{ Diabetic category } \\
\hline & \multicolumn{2}{|c|}{ Definite diabetes } & \multicolumn{2}{|c|}{ Probable diabetes } & \multicolumn{2}{|c|}{ Possible diabetes } & \multicolumn{2}{|c|}{ Abnormal GTT } \\
\hline & No. & $\%$ & No. & $\%$ & No. & $\%$ & No. & $\%$ \\
\hline I & 20 & $41 \cdot 7$ & 4 & $57 \cdot 1$ & 9 & $90 \cdot 0$ & 8 & 88.9 \\
\hline II & 23 & 47.9 & 2 & & 1 & & 1 & \\
\hline III & 5 & $10 \cdot 4$ & 1 & & & & & \\
\hline Total & 48 & $100 \cdot 0$ & 7 & $100 \cdot 0$ & 10 & $100 \cdot 0$ & 9 & $100 \cdot 0$ \\
\hline
\end{tabular}

of diabetes is shown in Table 7. The rates of retinopathy decreased significantly from $56 \%$ and $58 \%$ in the first 2 categories of severity of disease (definite and probable diabetes), to $31 \%$ in the third category (possible diabetes), and 19\% in the abnormal glucose tolerance test group $(p<0.01$ by a test for linear trend in proportions). These differences were more noticeable in cases of short duration than in those of 14-16 years or more than 16 years.

Advanced retinopathy was more prevalent among subjects with more severe metabolic abnormalities (Table 8). Diabetic retinopathy II was found in 25 out of $55(45.5 \%)$ subjects with definite or probable diabetes and in only 2 of $19(10.5 \%)$ of those with possible diabetes and abnormal GTT. Diabetic retinopathy III was present only in subjects with definite and probable diabetes.

The IIHDP data enable us to examine additional variables measured in 1963-8 for subjects followed up and examined in this survey. None of the following variables were found to be significantly related to retinopathy: area of birth, education, smoking habits, Quetelet index, peripheral vascular disease, blood pressure, total serum cholestrol, and high density lipoprotein (HDL) cholestrol. However, we did find that casual glucose values and serum uric acid values are related to retinopathy.

Table 9 shows mean casual blood glucose values by duration as found on the IIHDP examination performed in 1968. The mean of casual blood glucose values was significantly higher $(\mathrm{p}<0.001)$ among men with retinopathy at that time or who subsequently developed it than among those still free of this complication by $1978-80$. The relationship appears to be stable for all duration periods.

The mean serum uric acid values in 1963,1965, and 1968 according to diabetic duration and retinopathy are shown in Table 10. The mean serum uric acid level was lower among retinopathic diabetics for each duration period. The pooled differences between patients who developed retinopathy and those who did not are statistically significant $(p<0.01)$. This suggests that the development of retinopathy is preceded by a relatively low uric acid level which decreases progressively as the duration of diabetes increases.

\section{Discussion}

The IIHDP survey enables us to examine the occurrence of retinopathy among diabetic subjects identified in the study. The interpretation of the data on incidence and prevalence of diabetic retinopathy pertains to men of diverse ethnic groups aged 40 to 65 when they entered the survey. The conclusions based on the results of this study are limited by the death of $29 \%$ of the participants and by the dropping out of another $13 \%$ (Table 5).

This study has the advantage of the availability of many variables measured during the IIHDP in assessing the relationship of diabetic retinopathy to the other factors as a logical step in providing clues to the aetiology of this diabetic complication. While most of the surveys on the incidence and prevalence

Table 9 Casual blood glucose in 1968 in diabetic men with and without retinopathy in 1978-80

\begin{tabular}{|c|c|c|c|c|c|c|}
\hline \multirow{2}{*}{$\begin{array}{l}\text { Onset of diabetes } \\
\text { (duration and year) }\end{array}$} & \multicolumn{3}{|c|}{ With retinopathy } & \multicolumn{3}{|c|}{ Without retinopathy } \\
\hline & No. & $\begin{array}{l}\text { Mean blood } \\
\text { glucose } \\
(\mathrm{mg} / 100 \mathrm{ml})\end{array}$ & $S D$ & No. & $\begin{array}{l}\text { Mean blood } \\
\text { glucose } \\
(\mathrm{mg} / 100 \mathrm{ml})\end{array}$ & $S D$ \\
\hline Known before $1963(>16)$ & 18 & 186 & 63 & 13 & 133 & 47 \\
\hline Discovered $1963(\geqslant 16)$ & 13 & 161 & 51 & 14 & 129 & 33 \\
\hline Discovered $1965(14-16)$ & 16 & 168 & 72 & 21 & 132 & 48 \\
\hline Discovered $1968(11-13)$ & 17 & 194 & 67 & 56 & 162 & 24 \\
\hline
\end{tabular}

SI conversion: glucose $\mathrm{mg} / 100 \mathrm{ml} \times 0 \cdot 0555=\mathrm{mmol} / \mathrm{l}$. 
of retinopathy have been performed in selected diabetic cases, this is a population based study and not of patients specifically referred for medical care. Under the circumstances it was possible to compute the duration of diabetes by using the time of diagnosis as an accurate starting point. Such conditions are also pertinent in the studies of the Pima Indians, ${ }^{4}$ and they are essential in decreasing the disparity between known and actual duration of diabetes.

There was an increasing prevalence of retinopathy in the 178 diabetics examined in this study with increased duration of diabetes. These findings are consistent with previous studies ${ }^{1213}$ in showing the strong effect of duration in the development of diabetic retinopathy.

We noted that the prevalence of retinopathy declined from $49 \%$ in the 55-64 year old age group to a plateau of $36 \%$ in the 2 older age groups. One possible explanation of this decline is the high death rates among patients with retinopathy. ${ }^{14}$ This is partly supported by the fact that 3 times as many of the subjects who died during the follow-up period in our study already had retinopathy when examined in 1965 as compared with those who survived (Table 4).

Another variable that deserves high priority in the epidemiological research on diabetic retinopathy is hyperglycaemia or severity of diabetes, classified in our study in diabetic categories (Table 3 ). In order to assess the effect of severity of diabetes on the development of retinopathy we tabulated the prevalence of retinopathy by diabetic categories and duration (Table 7) and the type of retinopathy by diabetic categories (Table 8). In all duration groups the rate of retinopathy was relatively low among those with a low degree of diabetic severity at the time of diagnosis and high in those with an increased one. The disparity between the groups gradually diminished as duration increased. Advanced retinopathy was more prevalent in diabetic categories with severe metabolic abnormalities. It was also observed that the mean of casual blood glucose values was significantly higher among retinopathy subjects than in those free of retinopathy (Table 9).

Many clinical studies have reported a positive relationship between a high degree of glycaemia and risk of retinopathy. ${ }^{214-16}$ There were also suggestions that mitigation of hyperglycaemia has a protective effect against the development of retinopathy. ${ }^{17}$ However, other studies found no relationship between the level of glycaemia and the incidence of retinopathy. ${ }^{1819}$ Our findings support the view that the severity of diabetes and the degree of hyperglycaemia influence susceptibility to the development of retinopathy and its severity.

We have found no relationship between retinopathy and factors that have been implicated in the pre-

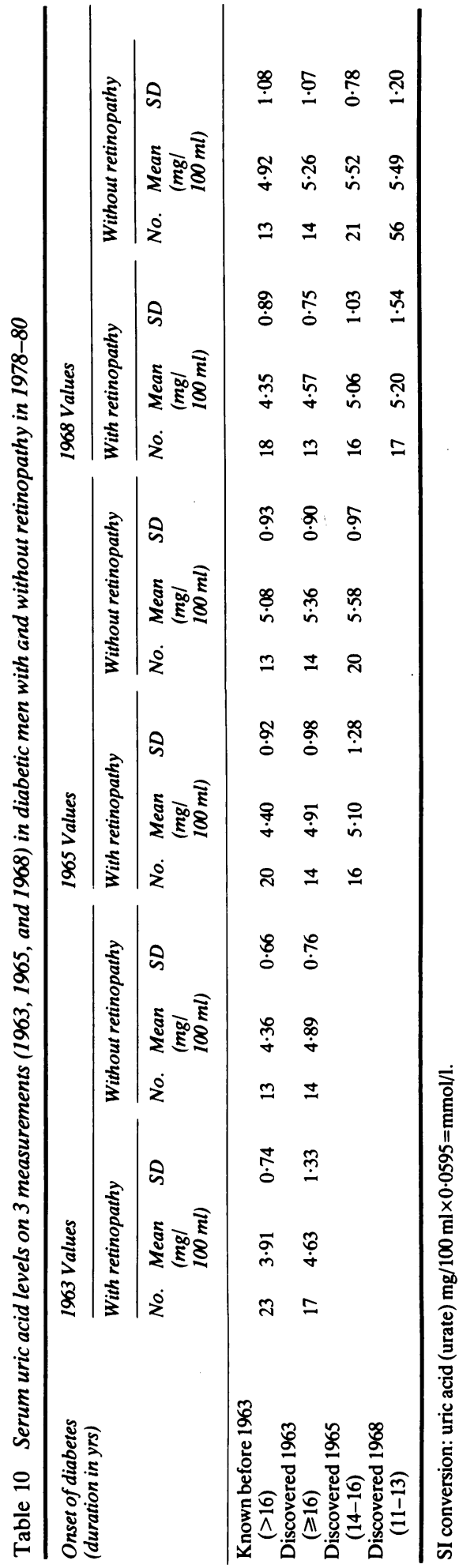


diction of coronary heart disease and/or diabetic vascular complications such as areas of birth, level of education, smoking habits, overweight, peripheral vascular disease, total serum cholestrol, HDL cholestrol, or blood pressure.

Probably the most significant finding of this study is the clear trend towards lower values of antecedent serum uric acid in men with retinopathy in $1978-80$ as compared with those not suffering from retinopathy. This was most distinctive in the diabetics of a long duration.

All the diabetics examined in the IIHDP had lower uric acid values than the nondiabetic subjects. ${ }^{8}$ Other studies have cited similar findings. ${ }^{2021}$ This relationship was interpreted as resulting from a competitive inhibition of uric acid reabsorbtion in the proximal renal tubules by glucose in persons with hyperglycaemia and glycosuria. ${ }^{11}$ Whether such increases in uric ácid excretion would cause even lower serum uric acid levels in diabetics prone to retinopathy is intriguing. To the best of our knowledge this report is the first to cite lower mean serum uric acid among diabetics who subsequently developed retinopathy as compared with those who did not. Additional epidemiological studies on this subject should shed light on the validity of our findings.

We thank Professor J. Abramson for helpful discussions, Professor J. Medalie and Dr J. B. Herman for their guidance, and Dr M. Shein for performing general examinations.

\section{References}

1 Report of the National Commission on Diabetes to the Congress of the United States Vol. III, Part 2, Scope and Impact of Diabetes (II). US Dep. HEW, Public Health Service, NIH DHEW Publ. No. (NIH) 77-1022: 15.

2 Burditt AF, Caird FI, Draper GJ. The natural history of diabetic retinopathy. Q J Med 1968; 37: 303-17.

3 Fukuda M. Natural history of diabetic retinopathy and its treatment in Japan. In: Baba S, Goto Y, Fukui I, eds. Diabetes mellitus in Asia. Amsterdam: Excerpta Medica, 1975: 390: 225-31.

4 Dorf A, Ballintine EJ, Bennett PH, Miller M. Retinopathy in
Pima Indians. Relationship to glucose level, duration of diabetes. age at diagnosis of diabetes, and age at examination in a population with a high prevalence of diabetes mellitus. Diabetes 1976; 25: 554-60.

5 Davis MD, MacCormick AJA, Haug GA, et al. Diabetic retinopathy, prevalence and importance. XXII Concilium Ophthalmologicum, Paris 1974. Acta Vol I, Masson, Paris, 1976; 165-74.

6 Groen JJ, Medalie JH Neufeld HN, et al. An epidemiologic investigation of hypertension and ischemic heart disease within a defined segment of the adult male population of Israel. Isr J Med Sci 1968; 4: 177-94

7 Medalie JH, Papier C, Herman JB, et al. Diabetes mellitus among 10000 adult men. I. Five-year incidence and associated variables. Isr J Med Sci 1974; 10: 681-97.

8 Herman JB, Mount FW, Medalie JH, et al. Diabetic prevalence and serum uric acid. Observations among 10000 men in a survey of ischemic heart disease in Israel. Diabetes 1967; 16: 858-68.

9 Medalie JH, Tzur B, Tamir S, Smith HA, Mount FW. Ischemic heart project. Methodological manual IV: procedure for tonometry and fundogram. Hadassah Medical Organization, 1965: 4: 111-4.

10 Michaelson IC, Eliakim M, Avshalom A, et al. An approach to the investigation of the vascular changes in the fundus of the eye in hypertension and arteriosclerosis. Excerpta Medica Int Cong Ser 1966; 146: 207-19.

11 Herman JB, Medalie JH, Goldbourt U. Diabetes, prediabetes and urecemia. Diabetologia 1976; 12: 47-52.

12 Goldberg MF. Natural history of diabetic retinopathy. Isr J Med Sci 1972; 8: 1311-5.

13 Kahn HA, Bradley RF. Prevalence of diabetic retinopathy. Age, sex and duration of diabetes. Br J Ophthalmol 1975; 59: 345-9.

14 Davies MD, Hiller R, Magli YL, et al. Prognosis for life in patients with diabetes; relation to severity of retinopathy. Trans Am Ophthalmol Soc 1979; 77: 144-70.

15 Bradley RF, Ramos E. The eye and diabetes. In: Marble A. White P, Bradley RF, Krall LP, eds. Joslin's diabetes mellitus. 11th ed. Philadelphia: Lea and Febiger, 1971: 478-525.

16 Hunter PR, Heath H, Bloom A. A clinical comparison between diabetics with no retinopathy after 15 years and severe deteriorating retinopathy. Diabetologia 1977; 13: 403 (abstr).

17 Hardin RC, Jackson RL, Johnston RL, Kelly HG. The development of diabetic retinopathy: effects of duration and control of diabetes. Diabetes 1956; 5: 397-404.

18 Colwell JA. Effect of diabetic control on retinopathy. Diabetes 1966; 15: 497-9.

19 Knowles HC Jr. Long-term juvenile diabetes treated with unmeasured diet. Trans Assoc Am Physicians 1971; 84: 95-101.

20 Beckett AG, Lewis JG. Gout and serum uric acid in diabetes mellitus. Q J Med 1960; 29: 443-58.

21 Mikkelsen WM. The possible association of hyperuricemia and/or gout with diabetes mellitus. Arthritis Rheum 1965; 8: 853-9. 